Published in final edited form as:

Front Biosci (Landmark Ed). ; 17: 30-39.

\title{
The hematopoietic stem cell niche
}

\author{
Dongsu Park ${ }^{1,2,3}$, David B. Sykes ${ }^{1,2,3}$, and David T. Scadden ${ }^{1,2,3}$ \\ ${ }^{1}$ Center for Regenerative Medicine and Cancer Center, Massachusetts General Hospital, 185 \\ Cambridge Street, Boston, MA, 02114, USA \\ ${ }^{2}$ Harvard Stem Cell Institute, 42 Church Street, Cambridge, MA, 02138, USA \\ ${ }^{3}$ Department of Stem Cell and Regenerative Biology, Harvard University, Divinity Avenue, \\ Cambridge, MA, 02138
}

\begin{abstract}
Hematopoietic stem cells (HSCs) possess the ability to self-renew and to differentiate to mature progeny along multiple different hematopoietic lineages. The function of HSCs depends upon the signals from surrounding cells found within the highly specialized microenvironment termed the hematopoietic stem cell niche. Understanding and exploiting the HSC niche is a goal of basic scientists and clinicians alike. Recent studies have focused on defining the cellular components and molecular factors critical to this microenvironment. Here we review recent findings, discuss unresolved questions, and examine the clinical implications of our current knowledge of the HSC niche.
\end{abstract}

\section{Keywords}

Hematopoietic Stem Cells; Niche; Osteoblasts; Endothelial Cells; Review

\section{INTRODUCTION \& DEFINITIONS}

1. HSC - The hematopoietic stem cell (HSC) is classically defined as a cell which, when transplanted into a recipient animal, can regerate all elements of the blood. There are specific cell-surface markers which define subsets of cells enriched with HSCs (e.g. $\mathrm{CD} 34^{+} \mathrm{CD} 38^{-}$cells in humans, and Lineage ${ }^{-} \mathrm{Kit}^{+} \mathrm{Sca}{ }^{+} \mathrm{CD} 48^{-} \mathrm{CD} 150^{+}$cells in mice). For the purposes of this review, we will use the term HSC as an all-encompassing term, given the high degree of variability within the cited articles. In other reviews, the term HSPC (hematopoietic stem/progenitor cell) has also been used to identify a less-well-defined population of cells which may include a mixture of both stem and progenitor cells). We will use the term HSC consistently throughout the text, realizing the limitations in defining this population when not all experiments can involve confirmation of HSC-activity through transplantation.

Send Correspondence to: David T. Scadden, 185 Cambridge Street, Boston, Massachusetts 02115, USA, Tel: 617-726-5615, Fax: 617-726-2662, dscadden@mgh.harvard.edu. 
2. HSC Niche - A specialized microenvironment that maintains HSC function. In adult human and rodents, bone marrow is the major site of hematopoiesis. However, the hematopoietic capacity of the bone marrow in humans is known to be different from that in rodents.

3. HSC Function - The capability of hematopoietic stem cells to undergo either self-renewal for the life-long maintenance of HSC pools or lineage differentiation for blood cell production, although evidence of single cell-mediated asymmetric self-renewal and differentiation has not been formally proven (1).

4. Negative effect on HSC Function - Loss of self-renewal in assays of serial transplantation or competitive transplantation

5. Positive effect on HSC Function - Advantage in assays of competitive transplantation when compared to wild type HSCs

6. Homing - Ability of the transplanted HSC to migrate into the bone marrow microenvironment of the recipient.

7. Endosteum - interface between bone and bone marrow where osteogenic cells reside

8. Sinusoidal vessels - specialized blood vessels with irregular and discontinuous endothelial cells abundant in bone marrow

9. Osteogenic cells - Bone forming cells along a spectrum of maturation, from the immature osteoprogenitors, aturing preosteoblasts, mature osteoblasts, and terminally differentiated osteocytes.

With few exceptions, most mammalian tissues are comprised primarily of terminally differentiated cells which are unable to proliferate. Therefore, tissue regeneration and repair depends on the division and differentiation of tissue stem or progenitor cells. In general, tissue stem cells make up a very small percentage of the total population and lack the functionality of their fully-differentiated progeny. Instead, tissue stem cells balance a tightly-regulated program of quiescence, self-renewal, and differentiation. This program is capable of responding to homeostatic and damage signals by generating new functional and differentiated cells. Dysregulation of this program can lead to malignancy or degenerative disease. While much of stem cell regulation is intrinsic, there is growing evidence that these decisions also depend on the specialized niche environment. The existence of the stem cell niche was first demonstrated while studying the behavior of stem cells in the ovary of Drosophila and of stem cells in the gonads of Caenorhabditis elegans $(2,3)$. In these models, the stem cells reside in specific locations surrounded by niche cells (e.g. the cap cells and hub cells in Drosophila ovary and testis respectively and the distal tip cells in Caenorhabditis elegans). Furthermore, in these models, the interaction with niche cells is critical in the stem cell fate decision to either symmetrically divide (where both daughter cells self-renew or both daughter cells differentiate) or asymmetrically divide (one daughter cell self-renews while one daughter cell differentiates) (2). These observations established a 
simple model of the niche in which stem cells remain in constant contact and receive signals and support from their surrounding cells.

Likewise, adult hematopoietic stem cells (HSCs) require signals and support from their microenvironment which in the human is the bone marrow, but in the mouse can be either bone marrow or spleen (4). This is perhaps most directly evident by the fact that, upon stem cell transplantation, donor HSCs home to the bone marrow where they establish life-long hematopoiesis in the recipient (5). Where in many tissue types, the physical structures of the tissues establish a fixed niche (e.g. the crypt cells of the small intestine (6)), regulation of the HSC in the dynamic environment of the bone marrow has added complexities. Firstly, the bone marrow microenvironment is comprised of a complex and heterogeneous population of cells (stromal cells). And secondly, the HSCs are not fixed, rather are capable of circulating, making their cell-cell interactions dynamic rather than static (7).

Defining the characteristics of the bone marrow niche as well as the mechanism of HSC regulation will be important milestones in our understanding of hematopoietic disorders. Our current model of treatment of malignant hematopoietic disorders generally involves the destruction of dysregulated cells (e.g. chemotherapeutic killing of leukemic stem cells). However, this model fails to address what could represent a new avenue for therapy: targeting the niche. Although many leukemias are known to arise in the setting of specific mutations, leading to the supposition that the disease is primarily cell-autonomous, only a fraction of these cells (i.e. the leukemic stem cells) have long-term repopulation potential. Furthermore, only a fraction of these cells manage to evade chemotherapy, contributing to disease relapse despite aggressive treatment. Growing evidence suggests that these surviving cells occupy and exploit the normal bone marrow niche as a source of protection (See review in detail) (8). The ability to target the interaction between the malignant cell and the microenvironment, disrupting the protective signal while sparing the normal HSCs, would be a welcome advancement in our treatment of leukemia.

Even in the setting of non-malignant disorders (e.g. bone marrow failure syndromes), where the approach has been the replacement of the diseased HSCs (e.g. via stem cell transplantation), there is growing evidence that part of the disease phenotype may be due to a deficiency in the niche or the niche-stem-cell interaction (9). Possessing the ability to restore deficient signals between the HSC and its niche would provide an innovative approach to the treatment of these non-malignant hematopoietic disorders. Many independent studies have identified cellular and extra-cellular components which make up the HSC niche. In this review we will discuss these recent insights with a focus on the dynamic relationship between the hematopoietic stem cell and the bone marrow microenvironment.

\section{COMPONENTS OF THE HSC NICHE}

\section{1. Osteogenic cells}

It has long been suspected that mesenchymal-derived cells in the bone marrow make up the important components of the niche. Early studies confirmed the concept of the HSC niche by demonstrating that HSCs required a specialized environment for the maintenance of their 
stem cell function and for induction of differentiation $(4,10)$. Subsequent studies showed that primitive hematopoietic cells reside near the endosteum of trabecular bones and that the endosteum is highly enriched in functional osteoblasts and sinusoidal vessels (11). In vitro studies in which human osteoblasts were co-cultured with human CD34+ cells (a population enriched for HSCs) demonstrated an expansion of stem cell number as well as better maintenance of "stem-ness", as shown in these studies by maintenance of long-term cultureinitiating cells (LTC-IC) assays $(12,13)$.

The role of osteoblastic cells in the HSC niche was further supported by in vivo functional studies showing that the genetic manipulation of osteoblastic cells can alter HSC function. The Col2.3 promoter ( $2.3 \mathrm{~kb}$ of the collagen 1 type I promoter) is expressed specifically in osteoblastic cells in adult mice $(14,15)$. Expression of a constitutively active PTH/PTHrP receptor (PPR) under the control of the Col2.3 promoter resulted in an increase in the number of osteoblastic cells and HSCs (16). Conditional inactivation of the bone morphogenetic protein receptor type IA (BMPRIA) in mouse bone marrow also increased the number of endosteal osteoblasts as well as the percentage of hematopoietic progenitor cells as measured by cell surface marker expression (Lineage-negative, c-Kit-positive, Sca-1-positive cells) (17). In a model of inducible ablation of osteoblastic cells (herpesvirus thymidine kinase gene expression under control of the Col2.3 promoter) resulted in severe pancytopenia and a decrease in the number of hematopoietic progenitor cells (18). In particular, the phenotype in this model was reversible, and discontinuation of ganciclovir permitted recovery of the osteoblasts as well as the hematopoietic progenitors. Taken together, these results support that the osteoblast lineage is clearly important for the regulation of $\mathrm{HSC}$ function.

More subtle genetic models have demonstrated the importance of a number of cell-signaling pathways between the osteoblast and the HSC. Osteoblast membrane and extracellular factors angiopoietin-1 (19), thrombopoietin (20), Wnt agonists inhibited by Dkk1 (21), and Notch ligand (after PPR activation) (16) preserve HSC function. In contrast, osteoblast products such as osteopontin $(22,23)$ negatively regulated long-term HSC quiescence (Figure 1).

Unlike the stem cells of other tissues, HSCs continuously circulate in the peripheral blood and require specific signals to home to the bone marrow niche. The circulation of HSCs follows a circadian rhythm controlled by the level of the chemokine/SDF-1a which can bind to the CXCL12 receptor on the surface of the HSCs (24-26). Noradrenaline signaling via beta-adrenergic receptors on the surface of $\mathrm{CD}_{3} 4^{+}$human HSCs and on mesenchymal cells in the niche increases HSC circulation (25). In fact, treatment with G-CSF (granulocyte colony stimulating factor) is known to increase the circulation of HSCs, and may do so via upregulation of the beta-adrenergic receptor expression (27). Whether osteoblastic cells are involved in the local secretion of cytokines such as CXCL12 or G-CSF, or whether this is a role of the other stromal or endothelial cells in the bone marrow has not been clearly elucidated.

HSC quiescence, the ability to remain in a noncycling state, is essential to preserving stem cell function $(19,28)$. Frequent exposure to stresses or aging signals cause HSCs to exit their 
quiescent state and leads to premature exhaustion of stem cell function (29-31). Taken together, these studies speak to the importance of the bone marrow microenvironment on long-term HSC function. The osteoblastic cells are critical components of the niche, and alterations in osteoblastic cells results in changes in HSC function. Osteoblastic cell association with HSCs plays a role in regulating HSC number and quiescence. During embryogenesis, osteoblast differentiation and bone development occurs before normal hematopoiesis is initiated in the bone marrow. These observations point towards a critical role of the osteogenic cells in HSC development and quiescence.

\section{2. Subsets of osteogenic cells}

The terminology of 'endosteal niche' refers to the enrichment of HSCs near the endosteal surface of the bone and the observation that alterations in endosteal osteoblastic cells contribute to HSC dysfunction. This region also contains abundant microvessels, sympathetic neurons and multiple different cells of hematopoietic and mesenchymal origin.

Osteoblast differentiation from osteogenic progenitors to terminally differentiated osteoblasts can be distinguished by changes in stage-specific genes. Genetic models manipulating different stages of osteoblast differentiation have focused on a number of systems to address this additional complexity. Sequential expression from a variety of promoters helps to identify the different stages of development. Runx2 is one of the earliest active promoters, followed by osterix $(O s x)$ in osteoprogenitors, the Col2.3 promoter ( $2.3 \mathrm{~kb}$ fragment of type I collagen) in maturing osteoblastic cells, osteocalcin (Ocn) in mature osteoblasts, and finally DMP1 in osteocytes (14). Unfortunately, these genetic stage separations do not correlate with reliable phenotypic markers to clearly label the different stages of osteogenic cells in vivo. Still, using lineage-specific inducible genetic models based on the outlined promoters, it has been possible to uncover important differences between the different stages of the osteolineage.

The study of hematopoiesis in transgenic mouse models in which osteogenic cells expressing thymidine kinase (TK) from the Col2.3 promoter has been compared to mice expressing TK from the osteocalcin promoter. Treatment with ganciclovir results in the death of those cells expressing TK. Col2.3-TK mice treated with ganciclovir show dramatic loss of bone marrow cellularity with deficiencies in lymphoid, erythroid, and myeloid progenitors, followed by decreases in the number of hematopoietic stem cells (HSCs) (18). However, in a mouse model of chronic inflammatory arthritis in which the mice display a severe defect in the number and function of mature osteoblasts, the HSCs appear normal as assayed by cell cycling parameters and long-term repopulation ability (32). This could be due to the support of less mature, non-bone forming osteoblasts which are not lost in this model of chronic inflammation, although the possibility that the residual mature osteoblast population in these mice is sufficient to provide the HSC niche has not been clearly excluded. Consistent with this finding, osteopontin (OPN), a matrix protein predominantly secreted from mature osteoblasts, is a negative regulator of HSC function and limits the size of the stem cell pool, perhaps providing a basis for the lack of positive correlation between HSCs and $\mathrm{OPN}^{+}$osteoblasts (22). 
As there is no such model to specifically ablate osteoprogenitors in adult bone, most studies have used osteoprogenitors derived from the bones of fetal mice in which osteogenesis is active and there is an abundance of less mature cells. The role of less mature osteoprogenitors as components of the HSC niche has been formally explored in models of osteoprogenitor-mediated ectopic bone formation and marrow reconstitution. Injection of osteoprogenitors (as identified by $\mathrm{CD} 105^{+}$and Thy $1^{-}$cell surface marker expression) under the kidney capsule of recipient mice can create donor-derived ectopic bone formation and a niche which host-derived HSCs can populate. In contrast, the subset of osteoprogenitors which are $\mathrm{CD}_{105^{+}}$and Thy $1^{+}$can form bone, but do not recruit HSCs (33). In addition, a recent real-time imaging study documented that the majority of HSCs were detected near or in contact with $\mathrm{N}$-cadherin ${ }^{+}$pre-osteoblastic cells in the endosteal surface of the trabecular bone (34), although this may not represent a specific interaction via $\mathrm{N}$-cadherin, especially given the controversy as to whether HSCs express N-cadherin themselves (35). Taken together, these results support the notion that mature osteoblasts are unlikely to have direct role in the support of HSCs, while more immature pre-osteoblasts are likely to participate in the HSC niche.

Beyond the importance of osteogenic cells in the maintenance of normal HSCs, our group has recently demonstrated that disruption of the osteogenic cells may actually induce dysplastic changes in neighboring HSCs (9). In this model, disruption of normal microRNA processing in the bone marrow microenvironment resulted in the development of myelodysplasia in the majority of animals, as well as frank leukemia harboring distinct genetic abnormalities in a small subset. In addition, comparing the role of osteoprogenitors and mature osteoblasts, the more immature osteogenic cells are felt to be critical for maintaining the integrity of hematopoiesis rather than mature osteoblasts. These results suggest a pivotal role of osteoprogenitors as the bone marrow microenvironment in HSC maintenance and suggest that further understanding may provide pathological and clinical insights into the development of MDS and leukemia (Figure 1).

Overall, growing evidence suggests that subpopulations of osteolineage cells are functional contributors to the HSC niche though the nature of the interactions, whether they are by direct contact or paracrine effect are still to be elucidated.

\section{3. Vascular contributions to the HSC niche}

Another potential cellular component of the HSC niche is the sinusoidal endothelial cells. It has been well documented that progenitor cells of megakaryocyte lineage are in close proximity to and regulated by endothelium (36). Evidence pointing to a potential role for endothelial cells serving as a HSC niche grew out of histologic studies using highly purified populations. The SLAM family markers $\left(\mathrm{CD} 48^{-} \mathrm{CD} 150^{+} \mathrm{CD} 41^{-}\right)$are capable of reliably labeling a very rare and very pure population of LT-HSCs ( 1 out of every 2.2 cells are longterm-HSCs) (37). Immunohistologic microscropy of HSCs with the SLAM family markers demonstrated that the majority of the $\mathrm{CD} 48^{-} \mathrm{CD} 150^{+} \mathrm{HSCs}$ were associated with the sinusoidal vasculature and that only $14 \%$ of this cell population was localized close to the endosteum (37). 
Bone marrow sinusoidal endothelial cells (SECs) express VEGFR2 and VEGFR3. A recent study demonstrated that conditional deletion of VEGFR2 in SECs could inhibit HSC engraftment and reconstitution (38). Whether this was due to issues of cell localization or support of HSC by the SEC could not be discerned. However, in vitro co-culture models suggest SECs can support HSC possibly through Notch-dependent manner (39).

One factor complicating the role of SECs in the HSC niche is the dynamic and circulating nature of the HSC, raising the possibility that the accumulation of HSCs near blood vessels is due simply to normal HSC trafficking through these blood vessels. Indeed, the conditional deletion of VEGFR2 in SECs did not result in hematopoietic defects for several weeks (38). This may suggest that SECs function in the homing and engraftment of HSCs, rather than for the maintenance of endogenous HSCs under homeostatic conditions.

The location of HSCs, vessels, and osteoblasts within intact bones was examined using high resolution, confocal in vivo video imaging technology (40). This study demonstrated that the 3-dimensional architecture of the endosteal region includes trabecular bone lining osteoblastic cells surrounding a rich microvascular network. These data argue that drawing a distinction between a perivascular and periosteoblastic niche is artificial. The anatomy indicates that these are very tightly associated structures. It is not clear that this is true throughout the bone marrow as most, but not all stem cells are located in the trabecular regions. HSC in diaphyseal areas may not be near trabeculae and therefore there may be perivascular niches in that context and there are almost surely perivascular niches in nonbony tissues like spleen and fetal liver.

It is likely that in the bone marrow the mesenchymal and vascular components interact in a cooperative fashion to regulate HSC. The vasculature clearly plays an essential role in the trafficking of HSC and delivery of the nutritional support for the tissue. Other paracrine features are still to be worked out, but are likely and likely to be regional. It has been shown previously that regional subsets of endothelial cells express the chemokine SDF-1a or CXCL12 and dictate the localization of injected HSC (41).

\section{4. Perivascular mesenchymal cells in the HSC niche}

The continuity of committed osteolineage cells and vascular structures in endosteal trabeculae suggests the close interaction of these tissue components. The mesenchymal populations that may serve as either osteolineage progenitors or other mesenchymal functions are also likely participants in regulated HSC. One report described that bone marrow perivascular reticulocytes also play a role in controlling hematopoietic stem cells. These reticular cells (CAR cells), an otherwise not well characterized mesenchymal population, express high amounts CXCL-12 $(42,43)$. It has been shown that MCAM/ $\mathrm{CD}_{146^{+}}$marrow stromal cells in humans are subendothelial reticulocytes residing in sinusoidal vessel wall and are a main source of angiopoietin-1 (44). Notably, CD146 ${ }^{+}$ subendothelial cells have been shown to be clonogenic in vivo and to recapitulate many ex vivo characteristics of mesenchymal/osteogenic stem cells. More recently, a rare Nestinpositive population of cells with mesenchymal stem cell (MSC) features has been shown to be in close association with the vasculature and with transplanted HSCs. Upon depletion of the Nestin ${ }^{+}$cells, HSC engraftment was severely reduced, suggesting that these Nestin- 
positive MSCs are participants in the HSC niche (45). Of note, these cells do respond to parathyroid hormone and are capable of yielding osteolineage descendent cells. They may therefore be the base of a hierarchy of mesenchymal cells affecting hematopoiesis (Figure $1)$.

\section{5. ADIPOCYTES}

The role of other types of mesenchymal stromal cells has also been studied, including bone marrow adipocytes. Until a recent study explored the effect of adipocytes in hematopoiesis, it was a question as to whether adipocytes were functional effectors of the HSC niche or whether they simply filled the unoccupied marrow space. It was demonstrated that the number and frequency of hematopoietic stem cells and short-term progenitors were dramatically reduced in adipocyte-rich vertebrae of the mouse tail. Using 'fatless' mouse models, which are genetically incapable of forming adipocytes, or in a parallel model of mice treated with a adipogenic inhibitor, (peroxisome proliferator-activated receptor-gamma inhibitor; PPARr inhibitor), marrow engraftment following irradiation was accelerated relative to the wild-type or untreated mice (46). These data implicate adipocytes as predominantly negative regulators of the bone-marrow microenvironment, and suggest that by inhibiting marrow adipogenesis may enhance hematopoietic recovery following bone marrow transplantation.

\section{LOCALIZATION OF HSCS WITHIN THE NICHE}

As mentioned, pinpointing the exact location of the hematopoietic stem cell in vivo within the bone marrow is difficult despite advancements in immunohistochemistry, genetic marking of cells, and in vivo imaging. Early studies showed that hematopoietic progenitor and stem cells were highly enriched near the endosteal bone surface, whereas more mature cells were selectively localized more centrally within the bone marrow cavity $(11,47)$.

More recently it was shown that transplanted HSCs could localize to spindle-shaped osteoblasts through a specific interaction via the type-1 transmembrane protein $\mathrm{N}$-cadherin on both the osteoblast cell and HSC surface (17). A follow-up study using real-time imaging confirmed the physical interaction between $\mathrm{N}$-cadherin-expressing osteogenic cells and green fluorescent protein labeled HSCs (34). Transplanted HSCs homed with greater efficiency to the endosteal bone surface; most localized within 2 cell diameters $(<15 \mu \mathrm{m})$ from $\mathrm{N}$-cadherin-positive osteoblasts and $40 \%$ were detected within 1 cell diameter $(<8 \mu \mathrm{m})$. However, the critical nature of the $\mathrm{N}$-cadherin interaction with HSCs has been called into question by conflicting results in the literature. One group in particular has published that highly purified HSCs do not express N-cadherin (48), and has shown that that deletion of Ncadherin from the HSCs does not alter the frequency and function of HSCs in vivo (35).

Another candidate molecule implicated in the association between the osteoblast and HSC is Tie2, a transmembrane tyrosine kinase found on HSCs which interacts with Ang-1 on the osteoblast cell surface. One study demonstrated signaling through Tie 2 could enhance the interaction between HSCs and osteoblasts. Furthermore, depletion of Tie2 from HSCs resulted in more active cell division and stem cell exhaustion both in vitro and in vivo, implicating Tie2 in the maintenance of HSC quiescence (19). 
Real-time imaging techniques examining isolated hematopoietic progenitors and osteoblasts revealed that a specialized membrane domain of HSCs was involved in prolonged contact with osteoblasts surface, inducing the delivery of signaling endosomes and resulting in elevated SDF-1a secretion from osteoblasts, thus providing a potential molecular mechanism governing physical interaction between HSCs and the osteogenic niche (49). Our recent in vivo imaging study further supports this notion showing that more primitive HSCs rapidly home to bone marrow and localize in close proximity to osteoblastic cells (at a distance of less than $10 \mu \mathrm{m})(40)$, suggesting that there is indeed preferred localization of HSCs within the bone marrow microenvironment where certain osteogenic cells and signals are provided.

The above studies demonstrate that HSCs are enriched at the endosteal surface of trabecular bones and suggest possible candidate molecules for the interaction between HSCs and osteoblastic cells. Still, the use of models in which purified fractions of stem or progenitor cells are transplanted may not reflect the frequency and localization of endogenous HSCs in vivo.

\section{CLINICAL IMPLICATIONS OF THE HSC NICHE}

Despite improvements in diagnosis, prognosis, and molecular profiling of hematopoietic malignancies, therapeutic advancements are lacking. The cornerstone cytotoxic chemotherapies in the treatment of acute myeloid and acute lymphoid leukemia (daunorubicin, cytarabine, and vincristine) have gone unchanged in three decades. Despite a brisk and often seemingly complete initial response to chemotherapy, most adult patients still eventually succumb to their disease due to relapse of chemotherapy-resistant cells. It is now clear that relapses are due to the 'minimal residual disease', that small population of leukemic cells which are able to survive. And there is growing evidence that the survival of these cells may depend on their interaction with the bone marrow microenvironment.

This concept of disease relapse due to the minimal residual disease of the leukemic cells mirrors the recovery of the normal hematopoietic stem cells following high-dose chemotherapy. Just as a small population of HSCs is capable of reconstituting the entire hematopoietic system, a small population of leukemic cells is capable of surviving and contributing to disease relapse. Furthermore, just as we believe that the survival of this small population of HSCs depends on their interactions with the niche, it is likely that the leukemic cells derive similar protective signals.

Currently, there are no known unique interactions which occur between leukemic cells and the niche. However, the goal of selectively targeting the niche of leukemic cells while sparing the niche of normal HSCs raises the exciting possibility of designing new therapies against that small population of cells contributing to disease relapse.

One concept, that of releasing or 'mobilizing' the leukemic cells from their protective niche environment, also stems from our understanding of normal HSCs. The chemokine CXCL12 acts as a powerful chemoattractant for HSCs which express the CXCR4 receptor. Osteoblastic cells express high levels of CXCL12 (50), as do the endothelial cells in the bone marrow. Following infusion, CXCL12 can help in the 'homing' of HSCs to the bone 
marrow. Furthermore, specific disruption of the CXCR4-CXCL12 axis can cause the release of HSCs from the bone marrow. This has been exploited clinically in the development of a CXCR4 antagonist (AMD3100, Plerixafor) which increases the number of circulating $\mathrm{CD} 34^{+}$cells as quickly as six hours after administration (51). In patients from whom one is collecting CD $34^{+}$stem cells from the periphery for stem cell transplantation, AMD3100 has been especially useful in ensuring adequate collection of cells. In animal models, it has been demonstrated that the use of AMD3100 affects leukemic cell sensitivity to chemotherapy through a putative mechanism of releasing leukemic cells from the protective environment of the niche (52). Clinical trials testing this concept are underway employing AMD3100 in the treatment of patients with myelodysplastic syndrome, acute myeloid leukemia, and multiple myeloma.

More than twenty years ago, it was shown that treatment of patients with granulocyte colony stimulating factor (G-CSF) increased the number of circulating progenitors (53). The mechanism of action of G-CSF and stem cell mobilization remains unclear, though investigators wondered whether treatment with G-CSF or GM-CSF (granulocytemacrophage colony stimulating factor) could sensitize the leukemic cells to chemotherapy. This possibility was balanced by the observation that many myeloid malignancies expressed the receptor for G-CSF or GM-CSF, raising the concern that treatment with the colony stimulating factors might actually stimulate cell proliferation and more aggressive disease. Human trials of 'priming' with G-CSF or GM-CSF in acute myeloid leukemias have suggested improvements in remission rates, but have failed to show a benefit in terms of overall survival $(54,55)$. More recent investigation has shown that signaling through the epidermal growth factor receptor (EGFR) may synergize with G-CSF in the mobilization of HSCs (56). It may be that priming with a combination of G-CSF and EGFR-inhibitors would mobilize leukemic cells from the niche and expose them to the toxic effects of chemotherapy.

As discussed earlier, the niche provides both protective signals as well as quiescence signals to HSCs. As cytotoxic chemotherapy acts primarily on dividing cells, a small population of quiescent leukemic cells may be therefore resistant. In addition to targeting the niche to release these leukemic cells, one would also like to trigger them to enter into the cell cycle and divide, thereby becoming sensitive to chemotherapy. In a mouse model of leukemia, treatment with G-CSF could indeed stimulate entry of leukemic cells into cycle, making them more sensitive to chemotherapy (57).

In addition to the prospect of targeting the niche in hematologic malignancies with the goal of interrupting the survival and quiescence signals, there has been growing concern that the niche, itself, may be a contributor to hematologic malignancy. Mice deficient for the retinoic acid receptor gamma (RAR-gamma) developed a myeloproliferative disorder due to the RAR-gamma-deficient microenvironment (58). When wild-type HSCs with normal RARgamma were transplanted into the RAR-gamma deficient mice, the myeloproliferative phenotype was maintained, demonstrating that the effect was not due to an HSCautonomous effect. Furthermore, mutations in micro-RNA processing in osteoprogenitors can initiate a myelodysplastic phenotype and, in a small number of animals, resulted in the development of acute myeloid leukemia with multiple genetic alterations (9). 
Overall, the development of hematologic malignancy may be a multi-step process involving mutations both autonomous to the hematopoietic cells as well as mutations in the supportive microenvironment. Targeting of the niche-HSC, niche-leukemic cell, or niche in hematopoietic malignancy is an attractive addition to the therapeutic armamentarium. Still, much work needs to be done to identify unique signals which will allow for elimination of leukemic residual disease while sparing the normal HSCs necessary to reconstitute the hematopoietic system following high-dose chemotherapy.

\section{CONCLUSIONS}

Unlike the stem cells from other tissues, hematopoietic stem cells are distinctive in the degree to which they migrate and circulate. They are difficult to study using static histologic sections where one must make assumptions on the steady state of the microenvironment. With the advances in imaging capability, it has become possible to demonstrate the microanatomy of the bone marrow microvenironment. By combining this with genetically engineered mouse models, we are beginning to understand the complex systems biology at play in the microenvironment. These studies have indicated populations of cells that are of particular importance in regulating HSC function. As the molecular details of those interactions in the normal and disease settings become more clear, interventions to more effectively induce changes in normal and malignant HSC may be forthcoming and yield novel ways to therapeutically manipulate hematopoiesis.

\section{Acknowledgments}

This work was supported by a Leukemia \& Lymphoma Society Fellowship award (D.P), American Society of Hematology Fellowship award (D.B.S), and grants of the National Institutes of Health (D.T.S.)

\section{REFERENCES}

1. Purton LE, Scadden DT. Limiting factors in murine hematopoietic stem cell assays. Cell Stem Cell. 2007; 1:263-70. [PubMed: 18371361]

2. Xie T, Spradling AC. A niche maintaining germ line stem cells in the Drosophila ovary. Science. 2000; 290:328-30. [PubMed: 11030649]

3. Crittenden SL, Bernstein DS, Bachorik JL, Thompson BE, Gallegos M, Petcherski AG, Moulder G, Barstead R, Wickens M, Kimble J. A conserved RNA-binding protein controls germline stem cells in Caenorhabditis elegans. Nature. 2002; 417:660-3. [PubMed: 12050669]

4. Schofield R. The relationship between the spleen colony-forming cell and the haemopoietic stem cell. Blood Cells. 1978; 4:7-25. [PubMed: 747780]

5. Osawa M, Hanada K, Hamada H, Nakauchi H. Long-term lymphohematopoietic reconstitution by a single CD34-low/negative hematopoietic stem cell. Science. 1996; 273:242-5. [PubMed: 8662508]

6. Flier, L. G. van der; Clevers, H. Stem cells, self-renewal, and differentiation in the intestinal epithelium. Annu Rev Physiol. 2009; 71:241-60. [PubMed: 18808327]

7. Adams GB, Alley IR, Chung UI, Chabner KT, Jeanson NT, Celso C. Lo, Marsters ES, Chen M, Weinstein LS, Lin CP, Kronenberg HM, Scadden DT. Haematopoietic stem cells depend on Galpha(s)-mediated signalling to engraft bone marrow. Nature. 2009; 459:103-7. [PubMed: 19322176]

8. Lane SW, Scadden DT, Gilliland DG. The leukemic stem cell niche: current concepts and therapeutic opportunities. Blood. 2009; 114:1150-7. [PubMed: 19401558]

9. Raaijmakers MH, Mukherjee S, Guo S, Zhang S, Kobayashi T, Schoonmaker JA, Ebert BL, Shahrour F. Al, Hasserjian RP, Scadden EO, Aung Z, Matza M, Merkenschlager M, Lin C, 
Rommens JM, Scadden DT. Bone progenitor dysfunction induces myelodysplasia and secondary leukaemia. Nature. 2010; 464:852-7. [PubMed: 20305640]

10. Wolf NS, Trentin JJ. Hemopoietic colony studies. V. Effect of hemopoietic organ stroma on differentiation of pluripotent stem cells. J Exp Med. 1968; 127:205-14. [PubMed: 5635040]

11. Gong JK. Endosteal marrow: a rich source of hematopoietic stem cells. Science. 1978; 199:14435. [PubMed: 75570]

12. Taichman RS, Emerson SG. Human osteoblasts support hematopoiesis through the production of granulocyte colony-stimulating factor. J Exp Med. 1994; 179:1677-82. [PubMed: 7513014]

13. Taichman RS, Reilly MJ, Emerson SG. Human osteoblasts support human hematopoietic progenitor cells in vitro bone marrow cultures. Blood. 1996; 87:518-24. [PubMed: 8555473]

14. Maes C, Kobayashi T, Kronenberg HM. A novel transgenic mouse model to study the osteoblast lineage in vivo. Ann N Y Acad Sci. 2007; 1116:149-64. [PubMed: 18083926]

15. Curcic, I. Bilic; Kronenberg, M.; Jiang, X.; Bellizzi, J.; Mina, M.; Marijanovic, I.; Gardiner, EM.; Rowe, DW. Visualizing levels of osteoblast differentiation by a two-color promoter-GFP strategy: Type I collagen-GFPcyan and osteocalcin-GFPtpz. Genesis. 2005; 43:87-98. [PubMed: 16149065]

16. Calvi LM, Adams GB, Weibrecht KW, Weber JM, Olson DP, Knight MC, Martin RP, Schipani E, Divieti P, Bringhurst FR, Milner LA, Kronenberg HM, Scadden DT. Osteoblastic cells regulate the haematopoietic stem cell niche. Nature. 2003; 425:841-6. [PubMed: 14574413]

17. Zhang J, Niu C, Ye L, Huang H, He X, Tong WG, Ross J, Haug J, Johnson T, Feng JQ, Harris S, Wiedemann LM, Mishina Y, Li L. Identification of the haematopoietic stem cell niche and control of the niche size. Nature. 2003; 425:836-41. [PubMed: 14574412]

18. Visnjic D, Kalajzic Z, Rowe DW, Katavic V, Lorenzo J, Aguila HL. Hematopoiesis is severely altered in mice with an induced osteoblast deficiency. Blood. 2004; 103:3258-64. [PubMed: 14726388]

19. Arai F, Hirao A, Ohmura M, Sato H, Matsuoka S, Takubo K, Ito K, Koh GY, Suda T. Tie2/ angiopoietin-1 signaling regulates hematopoietic stem cell quiescence in the bone marrow niche. Cell. 2004; 118:149-61. [PubMed: 15260986]

20. Yoshihara H, Arai F, Hosokawa K, Hagiwara T, Takubo K, Nakamura Y, Gomei Y, Iwasaki H, Matsuoka S, Miyamoto K, Miyazaki H, Takahashi T, Suda T. Thrombopoietin/MPL signaling regulates hematopoietic stem cell quiescence and interaction with the osteoblastic niche. Cell Stem Cell. 2007; 1:685-97. [PubMed: 18371409]

21. Fleming HE, Janzen V, Lo Celso C, Guo J, Leahy KM, Kronenberg HM, Scadden DT. Wnt signaling in the niche enforces hematopoietic stem cell quiescence and is necessary to preserve self-renewal in vivo. Cell Stem Cell. 2008; 2:274-83. [PubMed: 18371452]

22. Stier S, Ko Y, Forkert R, Lutz C, Neuhaus T, Grunewald E, Cheng T, Dombkowski D, Calvi LM, Rittling SR, Scadden DT. Osteopontin is a hematopoietic stem cell niche component that negatively regulates stem cell pool size. J Exp Med. 2005; 201:1781-91. [PubMed: 15928197]

23. Nilsson SK, Johnston HM, Whitty GA, Williams B, Webb RJ, Denhardt DT, Bertoncello I, Bendall LJ, Simmons PJ, Haylock DN. Osteopontin, a key component of the hematopoietic stem cell niche and regulator of primitive hematopoietic progenitor cells. Blood. 2005; 106:1232-9. [PubMed: 15845900]

24. Spiegel A, Kalinkovich A, Shivtiel S, Kollet O, Lapidot T. Stem cell regulation via dynamic interactions of the nervous and immune systems with the microenvironment. Cell Stem Cell. 2008; 3:484-92. [PubMed: 18983964]

25. Ferrer, S. Mendez; Lucas, D.; Battista, M.; Frenette, PS. Haematopoietic stem cell release is regulated by circadian oscillations. Nature. 2008; 452:442-7. [PubMed: 18256599]

26. Scadden DT. Circadian rhythms: stem cells traffic in time. Nature. 2008; 452:416-7. [PubMed: 18368105]

27. Spiegel A, Shivtiel S, Kalinkovich A, Ludin A, Netzer N, Goichberg P, Azaria Y, Resnick I, Hardan I, Hur H. Ben, Nagler A, Rubinstein M, Lapidot T. Catecholaminergic neurotransmitters regulate migration and repopulation of immature human CD34+ cells through Wnt signaling. Nat Immunol. 2007; 8:1123-31. [PubMed: 17828268] 
28. Sato T, Onai N, Yoshihara H, Arai F, Suda T, Ohteki T. Interferon regulatory factor-2 protects quiescent hematopoietic stem cells from type I interferon-dependent exhaustion. Nat Med. 2009; 15:696-700. [PubMed: 19483695]

29. Baldridge MT, King KY, Boles NC, Weksberg DC, Goodell MA. Quiescent haematopoietic stem cells are activated by IFN-gamma in response to chronic infection. Nature. 2010; 465:793-7. [PubMed: 20535209]

30. Passegue E, Ernst P. IFN-alpha wakes up sleeping hematopoietic stem cells. Nat Med. 2009; 15:612-3. [PubMed: 19498372]

31. Essers MA, Offner S, Blanco-Bose WE, Waibler Z, Kalinke U, Duchosal MA, Trumpp A. IFNalpha activates dormant haematopoietic stem cells in vivo. Nature. 2009; 458:904-8. [PubMed: 19212321]

32. Ma YD, Park C, Zhao H, Oduro KA Jr. Tu X, Long F, Allen PM, Teitelbaum SL, Choi K. Defects in osteoblast function but no changes in long-term repopulating potential of hematopoietic stem cells in a mouse chronic inflammatory arthritis model. Blood. 2009; 114:4402-10. [PubMed: 19759358]

33. Chan CK, Chen CC, Luppen CA, Kim JB, DeBoer AT, Wei K, Helms JA, Kuo CJ, Kraft DL, Weissman IL. Endochondral ossification is required for haematopoietic stem-cell niche formation. Nature. 2009; 457:490-4. [PubMed: 19078959]

34. Xie Y, Yin T, Wiegraebe W, He XC, Miller D, Stark D, Perko K, Alexander R, Schwartz J, Grindley JC, Park J, Haug JS, Wunderlich JP, Li H, Zhang S, Johnson T, Feldman RA, Li L. Detection of functional haematopoietic stem cell niche using real-time imaging. Nature. 2009; 457:97-101. [PubMed: 19052548]

35. Kiel MJ, Acar M, Radice GL, Morrison SJ. Hematopoietic stem cells do not depend on N-cadherin to regulate their maintenance. Cell Stem Cell. 2009; 4:170-9. [PubMed: 19119091]

36. Avecilla ST, Hattori K, Heissig B, Tejada R, Liao F, Shido K, Jin DK, Dias S, Zhang F, Hartman TE, Hackett NR, Crystal RG, Witte L, Hicklin DJ, Bohlen P, Eaton D, Lyden D, Sauvage F. de, Rafii S. Chemokine-mediated interaction of hematopoietic progenitors with the bone marrow vascular niche is required for thrombopoiesis. Nat Med. 2004; 10:64-71. [PubMed: 14702636]

37. Kiel MJ, Yilmaz OH, Iwashita T, Terhorst C, Morrison SJ. SLAM family receptors distinguish hematopoietic stem and progenitor cells and reveal endothelial niches for stem cells. Cell. 2005; 121:1109-21. [PubMed: 15989959]

38. Hooper AT, Butler JM, Nolan DJ, Kranz A, Iida K, Kobayashi M, Kopp HG, Shido K, Petit I, Yanger K, James D, Witte L, Zhu Z, Wu Y, Pytowski B, Rosenwaks Z, Mittal V, Sato TN, Rafii S. Engraftment and reconstitution of hematopoiesis is dependent on VEGFR2-mediated regeneration of sinusoidal endothelial cells. Cell Stem Cell. 2009; 4:263-74. [PubMed: 19265665]

39. Butler JM, Nolan DJ, Vertes EL, Finney B. Varnum, Kobayashi H, Hooper AT, Seandel M, Shido K, White IA, Kobayashi M, Witte L, May C, Shawber C, Kimura Y, Kitajewski J, Rosenwaks Z, Bernstein ID, Rafii S. Endothelial cells are essential for the self-renewal and repopulation of Notch-dependent hematopoietic stem cells. Cell Stem Cell. 2010; 6:251-64. [PubMed: 20207228]

40. Lo Celso C, Fleming HE, Wu JW, Zhao CX, Lye S. Miake, Fujisaki J, Cote D, Rowe DW, Lin CP, Scadden DT. Live-animal tracking of individual haematopoietic stem/progenitor cells in their niche. Nature. 2009; 457:92-6. [PubMed: 19052546]

41. Sipkins DA, Wei X, Wu JW, Runnels JM, Cote D, Means TK, Luster AD, Scadden DT, Lin CP. In vivo imaging of specialized bone marrow endothelial microdomains for tumour engraftment. Nature. 2005; 435:969-73. [PubMed: 15959517]

42. Sugiyama T, Kohara H, Noda M, Nagasawa T. Maintenance of the hematopoietic stem cell pool by CXCL12-CXCR4 chemokine signaling in bone marrow stromal cell niches. Immunity. 2006; 25:977-88. [PubMed: 17174120]

43. Omatsu Y, Sugiyama T, Kohara H, Kondoh G, Fujii N, Kohno K, Nagasawa T. The essential functions of adipoosteogenic progenitors as the hematopoietic stem and progenitor cell niche. Immunity. 2010; 33:387-99. [PubMed: 20850355]

44. Sacchetti B, Funari A, Michienzi S, Di Cesare S, Piersanti S, Saggio I, Tagliafico E, Ferrari S, Robey PG, Riminucci M, Bianco P. Self-renewing osteoprogenitors in bone marrow sinusoids can organize a hematopoietic microenvironment. Cell. 2007; 131:324-36. [PubMed: 17956733] 
45. Mendez-Ferrer S, Michurina TV, Ferraro F, Mazloom AR, Macarthur BD, Lira SA, Scadden DT, Ma'ayan A, Enikolopov GN, Frenette PS. Mesenchymal and haematopoietic stem cells form a unique bone marrow niche. Nature. 2010; 466:829-34. [PubMed: 20703299]

46. Naveiras O, Nardi V, Wenzel PL, Hauschka PV, Fahey F, Daley GQ. Bone-marrow adipocytes as negative regulators of the haematopoietic microenvironment. Nature. 2009; 460:259-63.

[PubMed: 19516257]

47. Nilsson SK, Johnston HM, Coverdale JA. Spatial localization of transplanted hemopoietic stem cells: inferences for the localization of stem cell niches. Blood. 2001; 97:2293-9. [PubMed: 11290590]

48. Kiel MJ, Radice GL, Morrison SJ. Lack of evidence that hematopoietic stem cells depend on Ncadherin-mediated adhesion to osteoblasts for their maintenance. Cell Stem Cell. 2007; 1:204-17. [PubMed: 18371351]

49. Gillette JM, Larochelle A, Dunbar CE, Schwartz J. Lippincott. Intercellular transfer to signalling endosomes regulates an ex vivo bone marrow niche. Nat Cell Biol. 2009; 11:303-11. [PubMed: 19198600]

50. Christopher MJ, Liu F, Hilton MJ, Long F, Link DC. Suppression of CXCL12 production by bone marrow osteoblasts is a common and critical pathway for cytokine-induced mobilization. Blood. 2009; 114:1331-9. [PubMed: 19141863]

51. Devine SM, Flomenberg N, Vesole DH, Liesveld J, Weisdorf D, Badel K, Calandra G, DiPersio JF. Rapid mobilization of CD34+ cells following administration of the CXCR4 antagonist AMD3100 to patients with multiple myeloma and non-Hodgkin's lymphoma. J Clin Oncol. 2004; 22:1095-102. [PubMed: 15020611]

52. Nervi B, Ramirez P, Rettig MP, Uy GL, Holt MS, Ritchey JK, Prior JL, Worms D. Piwnica, Bridger G, Ley TJ, DiPersio JF. Chemosensitization of acute myeloid leukemia (AML) following mobilization by the CXCR4 antagonist AMD3100. Blood. 2009; 113:6206-14. [PubMed: 19050309]

53. Duhrsen U, Villeval JL, Boyd J, Kannourakis G, Morstyn G, Metcalf D. Effects of recombinant human granulocyte colony-stimulating factor on hematopoietic progenitor cells in cancer patients. Blood. 1988; 72:2074-81. [PubMed: 3264199]

54. Lowenberg B, van Putten W, Theobald M, Gmur J, Verdonck L, Sonneveld P, Fey M, Schouten H, de Greef G, Ferrant A, Kovacsovics T, Gratwohl A, Daenen S, Huijgens P, Boogaerts M. Effect of priming with granulocyte colony-stimulating factor on the outcome of chemotherapy for acute myeloid leukemia. N Engl J Med. 2003; 349:743-52. [PubMed: 12930926]

55. Thomas X, Raffoux E, Botton S, Pautas C, Arnaud P, de Revel T, Reman O, Terre C, Corront B, Gardin C, Le QH, Quesnel B, Cordonnier C, Bourhis JH, Elhamri M, Fenaux P, Preudhomme C, Michallet M, Castaigne S, Dombret $\mathrm{H}$. Effect of priming with granulocyte-macrophage colonystimulating factor in younger adults with newly diagnosed acute myeloid leukemia: a trial by the Acute Leukemia French Association (ALFA) Group. Leukemia. 2007; 21:453-61. [PubMed: 17252021]

56. Ryan MA, Nattamai KJ, Xing E, Schleimer D, Daria D, Sengupta A, Kohler A, Liu W, Gunzer M, Jansen M, Ratner N, Cras T. D. Le, Waterstrat A, Van Zant G, Cancelas JA, Zheng Y, Geiger H. Pharmacological inhibition of EGFR signaling enhances GCSF-induced hematopoietic stem cell mobilization. Nat Med. 2010; 16:1141-6. [PubMed: 20871610]

57. Saito Y, Uchida N, Tanaka S, Suzuki N, Tomizawa-Murasawa M, Sone A, Najima Y, Takagi S, Aoki Y, Wake A, Taniguchi S, Shultz LD, Ishikawa F. Induction of cell cycle entry eliminates human leukemia stem cells in a mouse model of AML. Nat Biotechnol. 2010; 28:275-80. [PubMed: 20160717]

58. Walkley CR, Olsen GH, Dworkin S, Fabb SA, Swann J, McArthur GA, Westmoreland SV, Chambon P, Scadden DT, Purton LE. A microenvironment-induced myeloproliferative syndrome caused by retinoic acid receptor gamma deficiency. Cell. 2007; 129:1097-110. [PubMed: 17574023] 


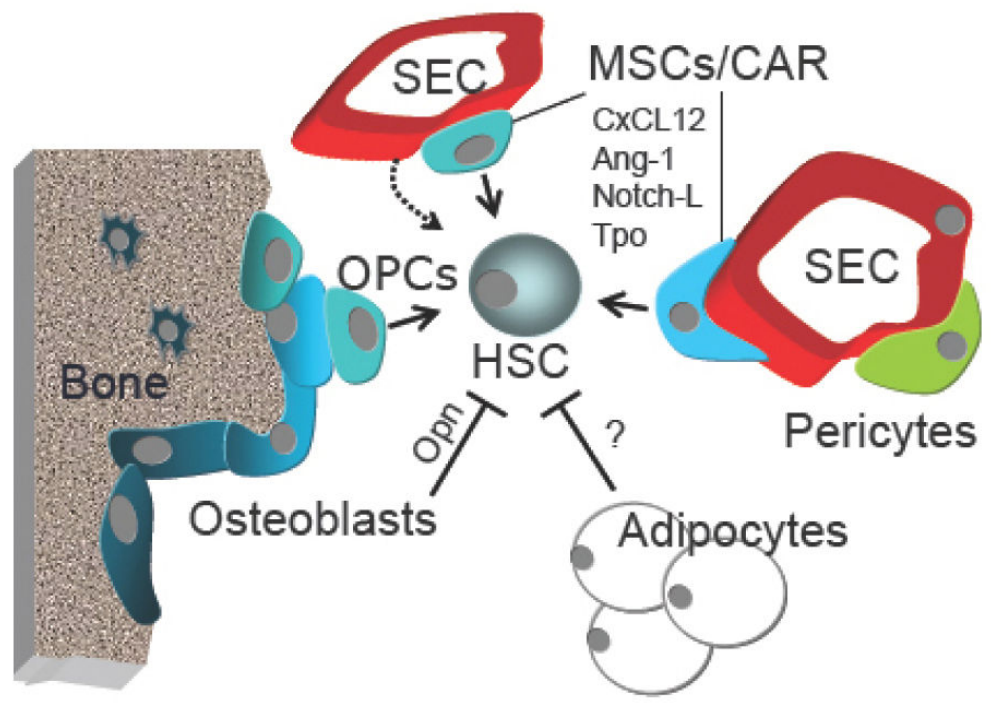

Figure 1.

In this model of the bone marrow microenvironment, the hematopoietic stem cell (HSC) receives a variety of signals from its niche. The signals are both positive (promote selfrenewal) and negative (decrease self-renewal) on the HSCs. Osteoprogenitor cells (OPCs) provide a positive signal, while the more mature osteopontin (Opn)-expressing osteoblasts provide a negative signal. Mesenchymal stem cells (MSCs)/CXCL12-abundant reticular (CAR) cells and other pericytes associate tightly with the sinusoidal endothelial cells (SEC) of bone marrow blood vessels and interact with the HSC. Adipocytes form another compartment of the bone marrow and are felt to be negative regulators of the HSC. 